\title{
Wheat yield benefited from increases in minimum temperature in the Huang-Huai-Hai Plain of China in the past three decades
}

\author{
Fulu Tao ${ }^{\mathrm{a}, \mathrm{c}, *}$, Dengpan Xiao ${ }^{\mathrm{a}, \mathrm{d}}$, Shuai Zhang ${ }^{\mathrm{a}}$, Zhao Zhang ${ }^{\mathrm{b}}$, Reimund P. Rötter ${ }^{\mathrm{e}}$ \\ a Key Laboratory of Land Surface Pattern and Simulation, Institute of Geographical Sciences and Natural Resources Research, Chinese Academy of Sciences, \\ Beijing 100101, PR China \\ b State Key Laboratory of Earth Surface Processes and Resource Ecology, Beijing Normal University, Beijing 100875, PR China \\ c Natural Resources Institute Finland (Luke), FI-00790 Helsinki, Finland \\ d Institute of Geographical Sciences, Hebei Academy of Sciences, Shijiazhuang 050011, Hebei, China \\ e Department of Crop Sciences, University of Göttingen, Grisebachstr. 6, Göttingen, Germany
}

\section{A R T I C L E I N F O}

\section{Article history:}

Received 10 December 2016

Received in revised form 4 February 2017

Accepted 26 February 2017

\section{Keywords:}

Agriculture

Climate change

Crop yield

Impact and adaptation

Heat stress

Phenology

\begin{abstract}
A B S T R A C T
Our understanding of climate impacts and adaptations on crop growth and productivity can be accelerated by analyzing historical data over the past few decades. We used crop trial and climate data from 1981 to 2009 at 34 national agro-meteorological stations in the Huang-Huai-Hai Plain (HHHP) of China to investigate the impacts of climate factors during different growth stages on the growth and yields of winter wheat, accounting for the adaptations such as shifts in sowing dates, cultivars, and agronomic management. Maximum $\left(T_{\max }\right)$ and minimum temperature $\left(T_{\min }\right)$ during the growth period of winter wheat increased significantly, by 0.4 and $0.6^{\circ} \mathrm{C} /$ decade, respectively, from 1981 to 2009, while solar radiation decreased significantly by $0.2 \mathrm{MJ} / \mathrm{m}^{2} /$ day and precipitation did not change significantly. The trends in climate shifted wheat phenology significantly at 21 stations and affected wheat yields significantly at five stations. The impacts of $T_{\max }$ and $T_{\min }$ differed in different growth stages of winter wheat. Across the stations, during 1981-2009, wheat yields increased on average by $14.5 \%$ with increasing trends in $T_{\text {min }}$ over the whole growth period, which reduced frost damage, however, decreased by $3.0 \%$ with the decreasing trends in solar radiation. Trends in $T_{\max }$ and precipitation had comparatively smaller impacts on wheat yields. From 1981 to 2009 , climate trends were associated with $\mathrm{a} \leq 30 \%$ (or $\leq 1.0 \%$ per year) wheat yield increase at 23 stations in eastern and southern parts of HHHP; however with a $\leq 30 \%$ (or $\leq 1.0 \%$ per year) reduction at 11 other stations, mainly in western part of HHHP. We also found that wheat reproductive growth duration increased due to shifts in cultivars and flowering date, and the duration was significantly and positively correlated with wheat yield. This study highlights the different impacts of $T_{\max }$ and $T_{\min }$ in different growth stages of winter wheat, as well as the importance of management (e.g. shift of sowing date) and cultivars shift in adapting to climate change in the major wheat production region.
\end{abstract}

(C) 2017 Elsevier B.V. All rights reserved.

\section{Introduction}

The potential impact of future climate change on agricultural production and food security has attracted considerable attention (e.g., Ortiz et al., 2008; Gornall et al., 2010; Lobell et al., 2011a, 2012; Müller et al., 2011; Porter et al., 2014). Many climate change

\footnotetext{
* Corresponding author at: Key Laboratory of Land Surface Pattern and Simulation, Institute of Geographical Sciences and Natural Resources Research, Chinese Academy of Sciences, Beijing 100101, PR China.

E-mail address: taofl@igsnrr.ac.cn (F. Tao).
}

impact studies make use of process-based crop models to assess consequences of future climate change for crop production or estimate the contribution of past climate changes to crop production. A process-based crop model has the strength of simulating the interactions between management and environmental conditions on the main processes of crop growth and development. Crop models have been routinely applied to assess the potential impacts of climate change on crop productivity since the late 1980s (White et al., 2011). However, the use of crop models for climate change impact studies is not without limitation. First, every crop model is a simplification of reality which takes some factors into account in greater detail than others. The assumptions and simplifications

http://dx.doi.org/10.1016/j.agrformet.2017.02.033 0168-1923/@ 2017 Elsevier B.V. All rights reserved. 


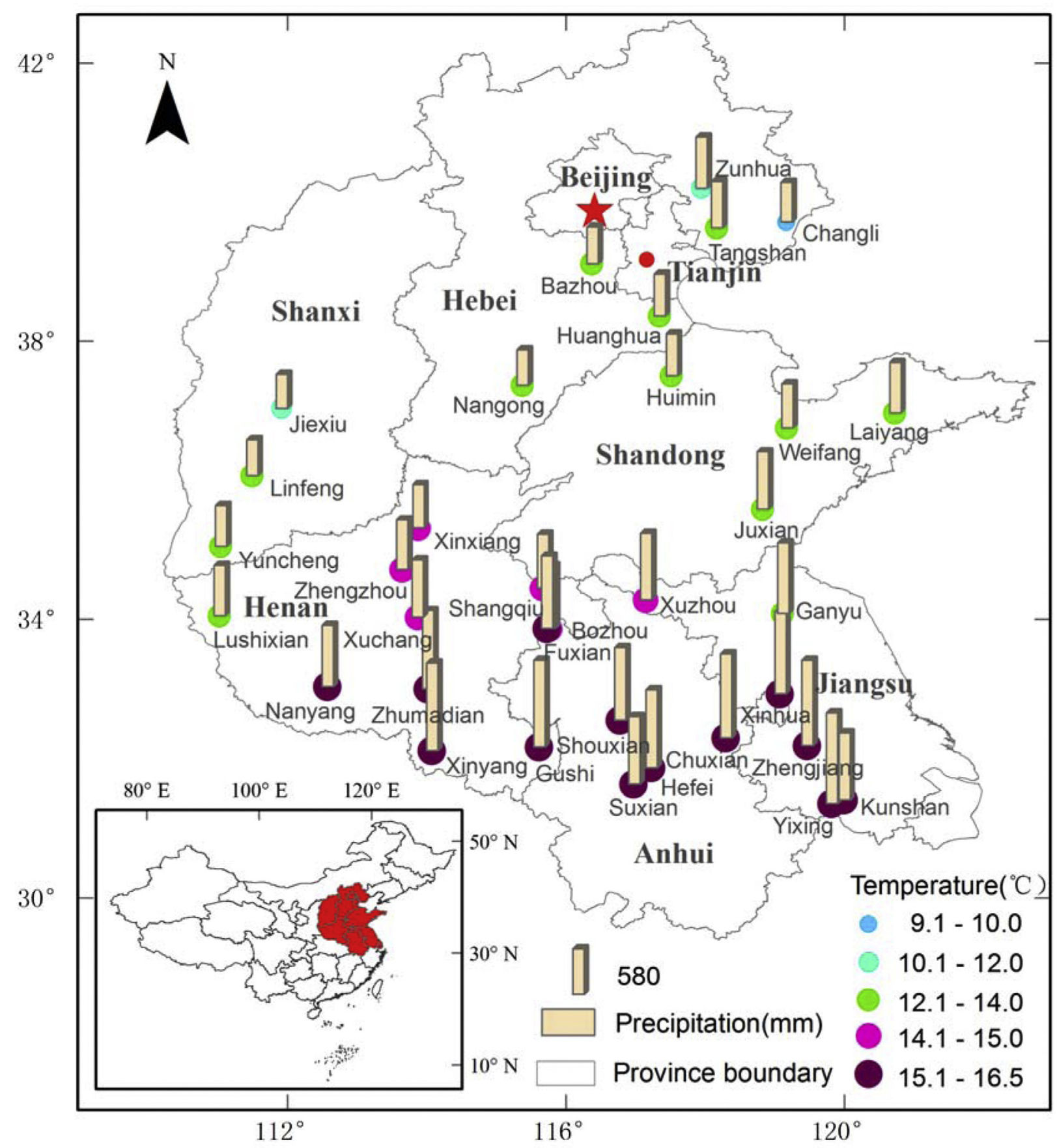

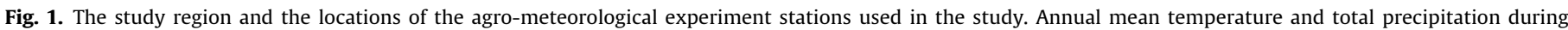
1981-2009 at each station are also shown.

made in a crop model are necessarily affected by preferences and idiosyncrasies of the model developers, based on their understanding and synthesis of the available scientific evidence at a given time, and the aims and constraints during the model development. Furthermore, with few exceptions (e.g. Sacks and Kucharik 2011) climate impact studies with crop models do not account for changes in crop varieties and management practices over time (Liu et al., 2010; Reidsma et al., 2010; Rötter et al., 2011; Tao et al., 2012a). Finally, key factors affecting crop yield such as pests, pathogens, weeds, soil quality deficits, flooding, and heat damage are very difficult to account for. Therefore, climate change impact assessments, performed with process-based crop models, may not properly represent the required or possible adaptations to a changing climate. On the other hand, a statistical model can quantify crop yields' response to climate change and account for other factors according to the information available, but the true behavior of crop growth may be very difficult to capture as a statistical model lacks physiological structure (Lobell and Burke, 2010).

Our understanding on climate impacts and adaptations of crop growth and productivity can be accelerated by analyzing historical experiences over the past few decades (Tao et al., 2012a,b; Palosuo et al., 2015). Along this line, recently, an increasing number of 
studies have investigated climate impacts on crop yields in a range of regions of the world using statistical models and long-term historical datasets of crop and climate (e.g., You et al., 2009; Reidsma et al., 2009; Welch et al., 2010; Lobell et al., 2011a; Tao et al., 2012b; Ray et al., 2015). Most of these studies have investigated the response of crop productivity to climate change and variability at a large scale such as the county, provincial or state, national and global scale, based on census data at that scale (You et al., 2009; Lobell et al., 2011a; Tao et al., 2012b; Ray et al., 2015). However, so far, only few studies have used long term crop trial data to examine how climate change has affected crop growth and productivity under adaptations in the field (e.g., Liu et al., 2010; Welch et al., 2010; Lobell et al., 2011b; Tao et al., 2012b).

Historical crop trial data, with accurate records of phenology, yield, weather, as well as cultivars and management practices, allow one to study how weather affects crop yield in a setting in which known agronomic management practices are taken based on actual weather (Welch et al., 2010; Lobell et al., 2011b; Tao et al., 2012a; Palosuo et al., 2015). Such diagnostic studies are more robust in understanding impact and adaptation mechanisms, improving crop models, and consequently have important implications for predicting the impact of future climate change on agricultural production (Welch et al., 2010; Lobell et al., 2011b; Tao et al., 2012a).

China is the greatest wheat producer in the world, producing about 120.4 Mt annually. And the Huang-Huai-Hai Plain (HHHP) is the primary winter wheat producing area in China (Yang, 1991; Lu and Fan, 2013), where wheat cultivation area takes up more than $60 \%$ of total wheat cultivation area in China. In this study, using crop trial data collected during the period 1981-2009 at 34 national agro-meteorological experiment stations across the HHHP, we investigated the climate-wheat yield relationship and the climate impact on wheat development and productivity in the past three decades using crop trial data collected during the period 1981-2009 at 34 national agro-meteorological stations across the Huang-Huai-Hai Plain (HHHP). Our objectives were to 1) investigate how climate during each growth stage of winter wheat had changed; and 2) understand how the climate change had affected the development and productivity of winter wheat, in the field in which agronomic management practices were taken based on actual weather.

\section{Data and methods}

\subsection{Experiment stations and data}

The study area is located in the HHHP, including Hebei, Henan, Shandong, Shanxi, Jiangsu and Anhui provinces, and Beijing and Tianjin Municipalities (Fig. 1). The typical cropping system is a rotation of winter wheat and summer maize in Hebei, Henan, Shandong and Shanxi provinces, and Beijing and Tianjin Municipalities; and rotation between winter wheat and rice in Anhui and Jiangsu provinces (Yang, 1991).

In this study, we selected 34 national agro-meteorological experiment stations, maintained by the Chinese Meteorological Administration, to investigate wheat-climate relationships. The purpose of these local agro-meteorological stations is to investigate local crop production and agricultural meteorological disasters, as well as provide suggestions for local farmers to manage agricultural meteorological disasters. There were 6 stations in Hebei province, 9 stations in Henan province, 4 stations in Shandong province, 3 stations in Shanxi province, 6 stations in Anhui province and 6 stations in Jiangsu province (Fig. 1). Annual average temperature and total precipitation of these selected stations during 1981-2009 are shown in Fig. 1. All stations are located in a winter wheat primary production region, and represent the typical cropping system in the HHHP. They are geographically and climatologically different, and have good records of weather variables and crop data during 1981-2009.

Daily weather data from 1980 to 2009, including maximum and minimum temperature, sunshine hours and precipitation for these agro-meteorological stations were obtained from the Chinese Meteorological Administration (CMA). Winter wheat trial data from 1981 to 2009 for the same station were also obtained from the CMA. These data included phenology, yields, cultivar and agronomic management practices. The detailed phenological records, including the dates of wheat sowing, emergence, winter dormancy, greenup (recovery from dormancy), anthesis and maturity, at the experimental stations provide a unique chance to investigate relationships between weather variables and farm-specific sowing and harvesting dates and wheat growth phases. Crop management practices at the agro-meteorological experimental stations were similar to local farming practices. That is: cultivar choice, dates of sowing and harvesting, and application of fertilizer and irrigation water was in accordance with farmer practice in the region. Irrigation and fertilizer was applied several times every year, and pesticides were used to control pests and diseases. During the study period, due to interannual weather variability and agronomic management, sowing dates were shifted and due to breeding progress cultivars were changed every 3-5 years.

Average maximum temperature $\left(T_{\max }\right)$ and minimum temperature $\left(T_{\min }\right)$, solar radiation $(S R D)$ and accumulated precipitation $(P)$ during the five growth stages of winter wheat, i.e., GP1 (from emergence date to winter dormancy date), GP2 (from winter dormancy date to greenup date), GP3 (from greenup date to anthesis date), GP4 (from anthesis date to maturity date) and GPw (the whole growth period from emergence date to maturity date), were calculated to investigate the impacts of climate at different growth stages on annual wheat yield. Solar radiation at some stations was estimated using bright sunshine hours observations and the Angström-Prescott equation (Prescott, 1940). Across the stations, the root-mean-square error between the estimated and observed SRD was less than $3.0\left(\mathrm{MJ} \mathrm{m}^{-2} \mathrm{day}^{-1}\right)$ and the coefficient of determination was more than 0.8 .

\subsection{Methods}

First, at each growth period and each station, time trends in major climate variables including $T_{\max }, T_{\min }, S R D$ and $P$ during 1981-2009 were analyzed using univariate linear regression. The Durbin-Watson statistic was conducted to test the null hypothesis that the residuals from an ordinary least-squares regression are not auto-correlated. Statistical significance was tested using the twotailed $t$-test. Likewise, trends in the major phenological dates and wheat growth duration were analyzed.

Then, for each growth stage at each station, partial correlation analyses were conducted to investigate the relationship between annual wheat yields and each of the four major climate variables (i.e., $T_{\max }, T_{\min }, S R D$ and $P$ ) that affect crop growth and productivity most (Peng et al., 2013). The partial correlation analyses were conducted based on linearly detrended yields series and linearly detrended climate variables series (Peng et al., 2013). Detrending yield series (i.e., using the residuals from a linear regression of yield with time) is a commonly used method to separate the impacts of climate variability from those of varieties and management technology on yields (Lobell and Asner, 2003).

Next, we applied a multiple regression model to estimate the sensitivity of yield to climate variables for each growth stage at each station during 1981-2009. The model was of the form

$Y d_{t}=\beta_{0}+\beta_{1} t+\beta_{i 2} T_{\max t i}+\beta_{i 3} T_{\min t i}+\beta_{i 4} P_{t i}+\beta_{i 5} S R D_{t i}+\varepsilon_{t}$ 


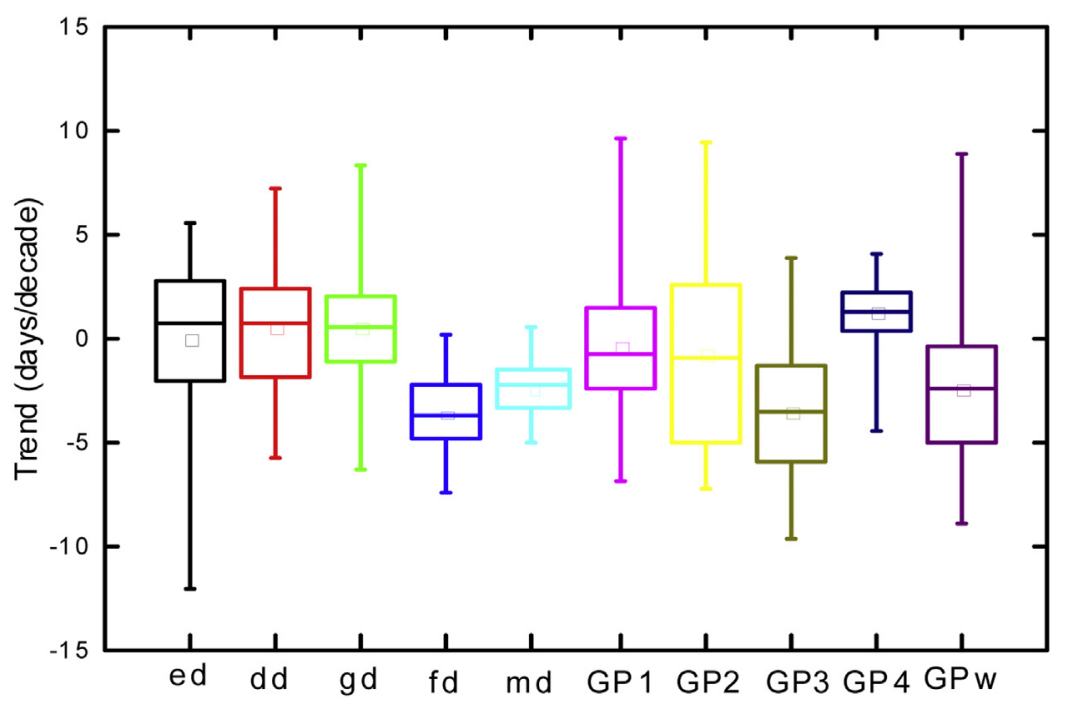

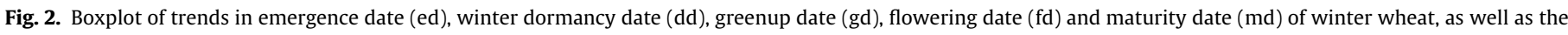

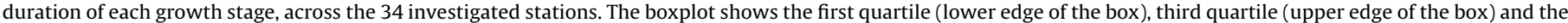
median (horizontal line in the middle of the box) and the mean (square). The whiskers represent the range from 1 to 99 percentiles of the data.

where $Y d_{\mathrm{t}}$ represents annually observed yields in year $t, \beta_{0}$ represents the intercept. $\beta_{1}$ is the station-specific linear time trend, which represents the yield trend at the station due to improvements in varieties, technology and management over the study period. $\beta_{i 2}, \beta_{i 3}, \beta_{i 4}$, and $\beta_{i 5}$ are model parameters representing the sensitivity of yield to changes in $T_{\max }, T_{\min }, P$ and $S R D$ at $i$-th growth stage, respectively. $\varepsilon_{t}$ is an error term. $T_{\max t i}, T_{\min t i}, P_{t i}$ and $S R D_{t i}$ are the average $T_{\max }, T_{\min }, P$ and $S R D$ during $i$-th growth stage (i.e., GP1, GP2, GP3, GP4 and GPw), respectively, in year $t$ at a station. We focused on the major effects of each important climate variable; therefore, the interactions between the climate variables are not included here.

For each growth stage at each station, a set of parameters $\beta_{0-5}$ for Eq. (1) were estimated. Statistical significance of the parameters was tested using the two-tailed $t$-test. Owing to the limited historical sample size, a bootstrap resampling approach was used to estimate sampling uncertainty associated with the derived regression coefficients, in which the historical data were resampled and a new regression model was fit to the data. In each case, 1000 bootstrap samples were used and the median estimates were used in further analyses. The median estimates of $\beta_{i 2}, \beta_{i 3}, \beta_{i 4}$, and $\beta_{i 5}$ represent the sensitivity of yield to changes in $T_{\max }, T_{\min }, P$, and $S R D$ during $i$-th growth stage, respectively, at a station and a growth stage, which was further expressed in percentage yield change per year per unit in the independent variable:

$\beta_{\mathrm{ij}}=\beta_{i j} / Y d_{m} * 100 \%$

where $Y d_{\mathrm{m}}$ is the observed mean yield at a station during 1981-2009.

Finally, for each growth stage at each station, we estimated climate impacts on yield during 1981-2009. According to the Eq. (1), the impact of changes in $T_{\max }, T_{\min }, P$, and $S R D$ on yield during 1981-2009 for $i$-th growth stage at a station, i.e., $\Delta Y d_{-} T_{\operatorname{maxi}}$, $\Delta Y d_{-} T_{\text {mini }}, \Delta Y d_{-} P_{i}$ and $\Delta Y d_{-} S R D_{i}$, was estimated by Eqs. (3)-(6), respectively, as follows,

$\Delta Y d_{-} T_{\max i}=\beta_{\mathrm{i} 2} \Delta T_{\max i}$

$\Delta Y d_{-} T_{\min i}=\beta_{\mathrm{i} 3} \Delta T_{\min i}$

$\Delta Y d_{-} P_{i}=\beta_{\mathrm{i} 4} \Delta P_{i}$

$\triangle Y d S R D_{i}=\beta_{\mathrm{i} 5} \Delta S R D_{i}$ where $\Delta Y d_{-} T_{\operatorname{maxi}}, \Delta Y d_{-} T_{\operatorname{mini}}, \Delta Y d_{\perp} P_{i}, \Delta Y d_{-} S R D_{i}$ are yield change over 29 years (taking the mean as a reference) due to changes in $T_{\max }, T_{\min }, P$ and $S R D$ from 1981 to 2009 at $i$-th growth stage. $\Delta T_{\text {maxi, }}$ $\Delta T_{\text {mini, }} \Delta P_{i}, \Delta S R D_{i}$ are changes in $T_{\max }, T_{\min }, P$ and $S R D$ from 1981 to 2009 at $i$-th growth stage, which were estimated by regressing $T_{\max }$, $T_{\min }, P$ and $S R D$ on time and multiplied the slope of the regression by the time duration.

According to Eq. (1), the impact of climate change jointly on crop yields during 1981-2009 for $i$-th growth stage at a station $\left(\Delta \mathrm{Yd}_{-} \mathrm{clim}_{\mathrm{i}}\right)$ was estimated as:

$\Delta Y d_{-} \operatorname{clim}_{i}=\beta_{i 2} \Delta T_{\max i}+\beta_{i 3} \Delta T_{\min i}+\beta_{i 4} \Delta P_{i}+\beta_{i 5} \Delta S R D_{i}$

For comparison, at each station we also applied a multiple regression model with the climate variables in all the four growth stages as independent variables:

$$
\begin{aligned}
& Y d_{t}=\beta_{0}+\beta_{1} t+\beta_{12} T_{\max } t 1+\beta_{13} T_{\min t 1}+\beta_{14} P_{t 1}+\beta_{15} S R D_{t 1} \\
& +\beta_{22} T_{\max t 2}+\beta_{23} T_{\min t 2}+\beta_{24} P_{t 2}+\beta_{25} S R D_{t 2} \\
& +\beta_{32} T_{\max t 3}+\beta_{33} T_{\min t 3}+\beta_{34} P_{t 3}+\beta_{35} S R D_{t 3} \\
& +\beta_{42} T_{\max t 4}+\beta_{43} T_{\min t 4}+\beta_{44} P_{t 4}+\beta_{45} S R D_{t 4}+\varepsilon_{t}
\end{aligned}
$$

where $\beta_{i 2}, \beta_{i 3}, \beta_{i 4}$ and $\beta_{i 5}$ represent the sensitivity of yield to changes in $T_{\max }, T_{\min }, P$, and SRD at $i$-th growth stage, respectively. $T_{\text {maxti }}, T_{\text {minti }}, P_{\mathrm{ti}}$ and $S R D_{\mathrm{ti}}$ represent the mean $T_{\max }, T_{\min }, P$, and $S R D$ at $i$-th growth stage in year $t$, respectively.

Then, the impact of climate change jointly on crop yields during 1981-2009 at a station ( $\Delta$ Yd_clim) was estimated as:

$$
\begin{aligned}
& \Delta Y d_{-} c \lim =\beta_{12} \Delta T_{\max 1}+\beta_{13} \Delta T_{\min 1}+\beta_{14} \Delta P_{1}+\beta_{15} \Delta S R D_{1} \\
& +\beta_{22} \Delta T_{\max 2}+\beta_{23} \Delta T_{\min 2}+\beta_{24} \Delta P_{2}+\beta_{25} \Delta S R D_{2} \\
& +\beta_{32} \Delta T_{\max 3}+\beta_{33} \Delta T_{\min 3}+\beta_{34} \Delta P_{3}+\beta_{35} \Delta S R D_{3} \\
& +\beta_{42} \Delta T_{\max 4}+\beta_{43} \Delta T_{\min 4}+\beta_{44} \Delta P_{4}+\beta_{45} \Delta S R D_{4}
\end{aligned}
$$

where $\Delta T_{\text {maxi, }} \Delta T_{\text {mini, }} \Delta P_{i}$ and $\Delta S R D_{i}$ are changes in $T_{\max }, T_{\min }, P$ and $S R D$ at $i$-th growth stage from 1981 to 2009, respectively. 


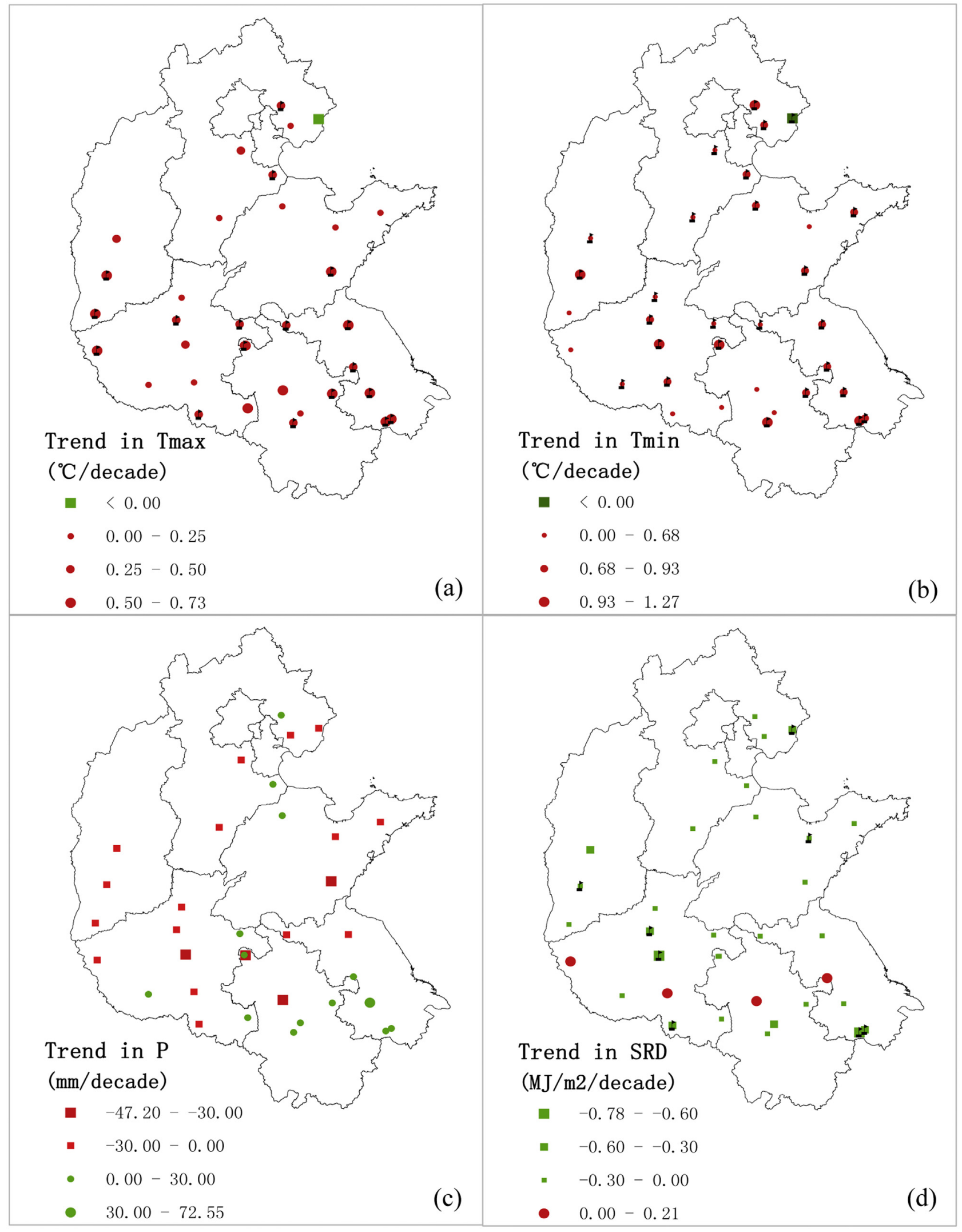

Fig. 3. Trends in maximum temperature (Tmax) (a), minimum temperature (Tmin) (b), precipitation $(P)(\mathrm{c})$ and solar radiation (SRD) (d) over whole growth period GPw of winter wheat during 1981-2009. Stations with a trend significant at the 0.05 level are marked by a flag. 

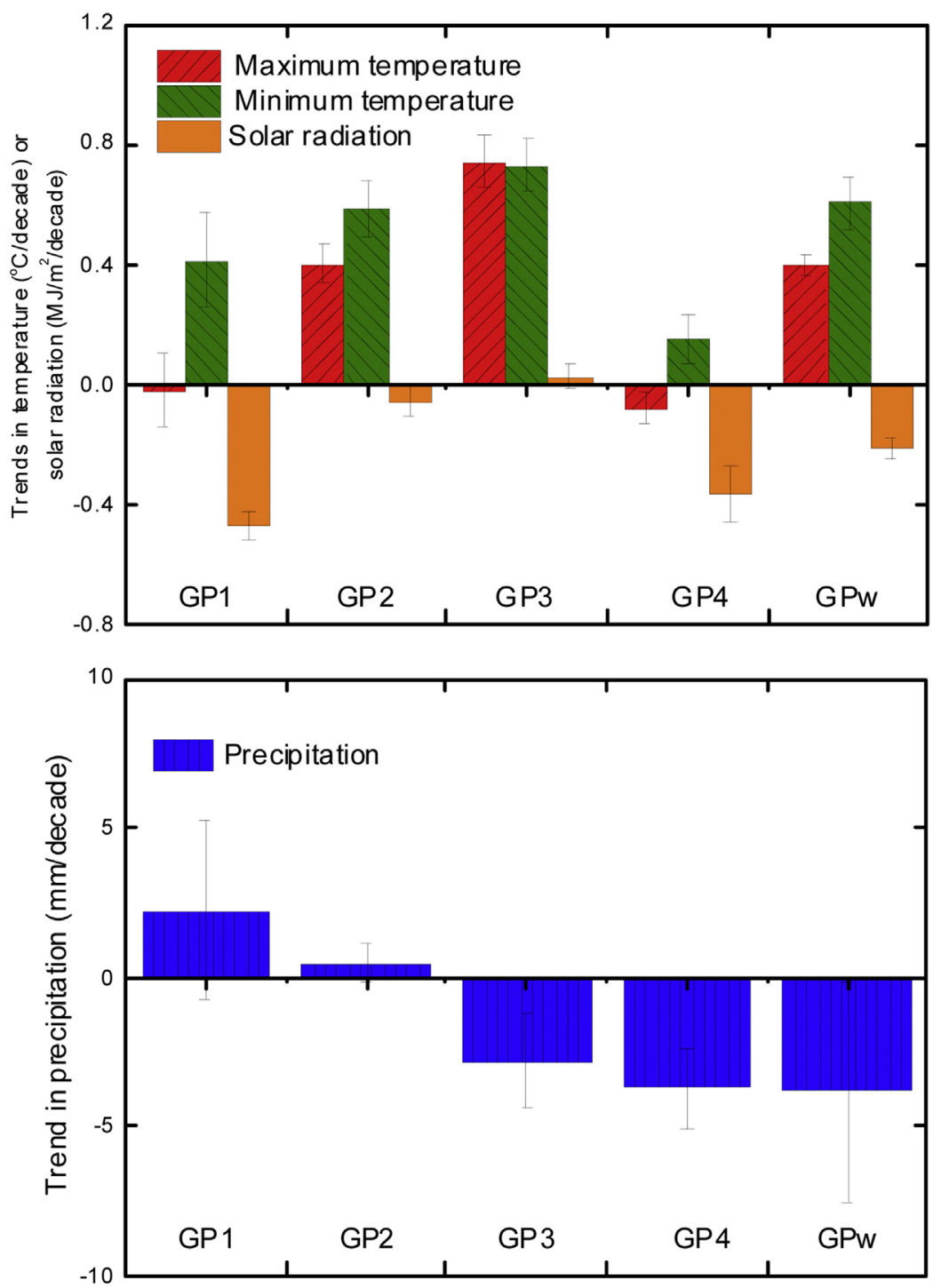

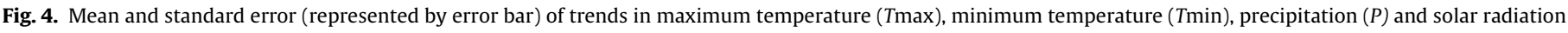
$(S R D)$ at each growth stage of winter wheat across the 34 investigated stations.

\section{Results}

\subsection{Changes in phenology and wheat growth duration and its relation to yield}

The phenology of winter wheat changed significantly over the period 1981-2009 (Fig. 2). From all 34 investigated stations, the trends in emergence dates and sowing dates were similar, suggesting emergence dates were closely associated with sowing dates. The dates of emergence, winter dormancy and greenup were delayed on average by $0.05,0.5$ and 0.5 days/decade, respectively. In contrast, the dates of anthesis and maturity become earlier on average by 3.6 and 2.4 days/decade, respectively. As a result, GP1, GP2 and GP3 were shortened on average by $0.4,0.8$, and 3.5 days/decade, respectively. By contrast, GP4 was prolonged on average by 1.2 days/decade. Finally, GPw was shortened on average by 2.4 days/decade. In summary, although the lengths of GP2 and GP3 were reduced, the length of GP4, i.e. the duration of grain filling stage, was prolonged under the combined effects of climate change and cultivar shifts (Fig. 2).

Such changes in wheat phenology and growth duration are likely to have contributed to yield changes. Further analyses showed that wheat yields were significantly and positively correlated to the length of GP2, GP4, and GPw (Fig.S1). Thus, decreases in lengths of GP2 and GPw would tend to lower wheat yields, whereas an increasing length of GP4, as shown in Fig. 2, would tend to increase wheat yield over time.

\subsection{Climate trends in the wheat growing period in the HHHP during 1981-2009}

The stations, located in various geographical and climate zones, showed diverse climatic trends (Fig. 3). Significant warming trends were observed over GPw during 1981-2009. From the investigated 34 stations, warming trends in $T_{\max }$ were significant $(p<0.05)$ at 18 stations (Fig. 3a), and warming trends in $T_{\min }$ were significant $(p<0.05)$ at 26 stations (Fig. $3 b) . T_{\max }$ and $T_{\min }$ decreased at only one station. $P$ decreased at 21 stations, but not significantly (Fig. 3c). $S R D$ decreased at 30 stations, and significantly at 8 stations (Fig. $3 \mathrm{~d}$ ).

Across the stations in the HHHP, on average, $T_{\max }$ and $T_{\min }$ during GPw increased by $0.40^{\circ} \mathrm{C} /$ decade and $0.61^{\circ} \mathrm{C} /$ decade, respectively, whereas $S R D$ and $P$ decreased by $0.21 \mathrm{MJ} / \mathrm{m}^{2}$ and $3.9 \mathrm{~mm} /$ decade, respectively, during 1981-2009 (Fig. 4). Climate trends varied across the stations and among different wheat growth 


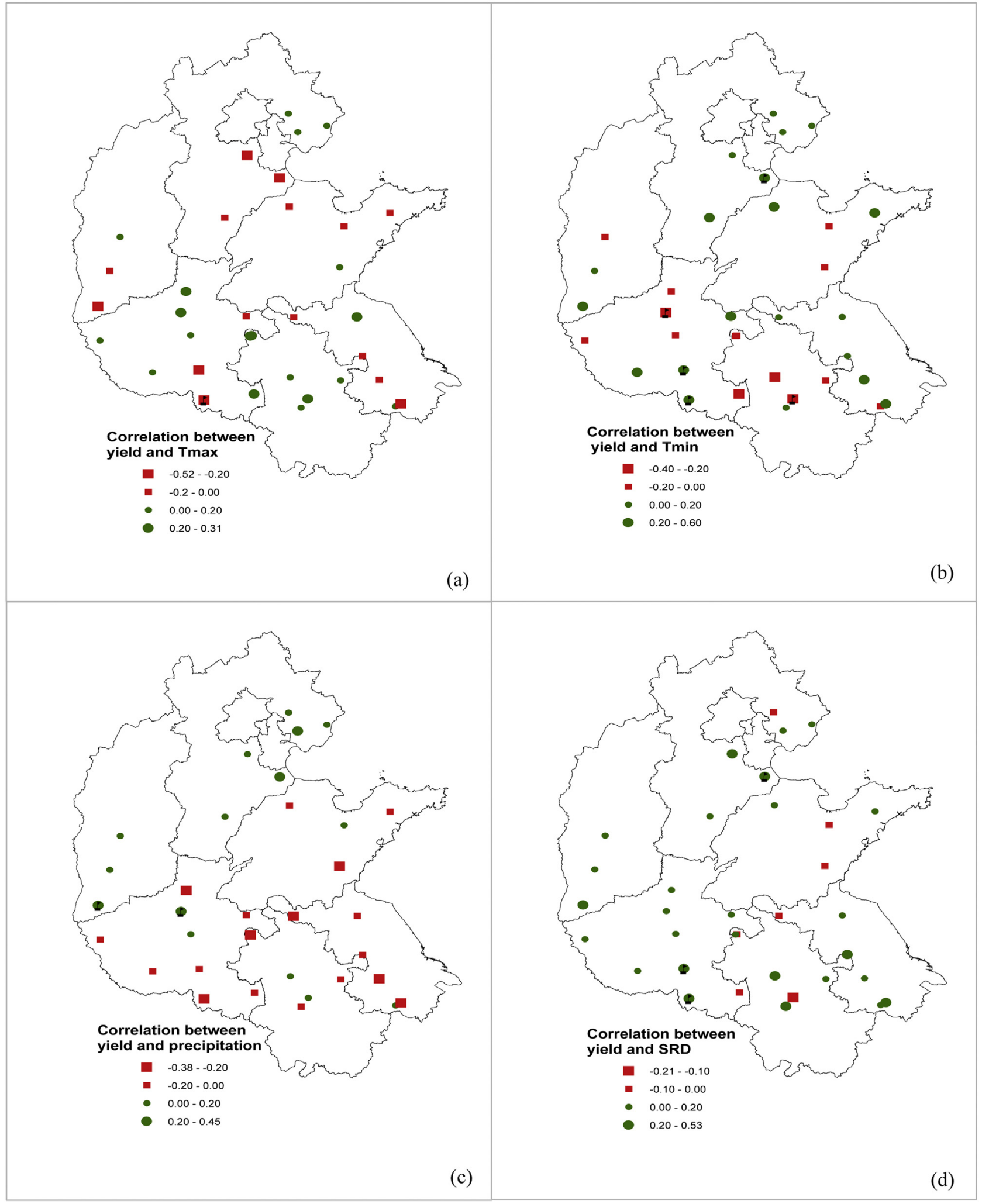

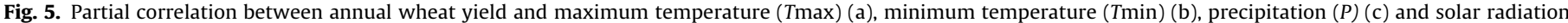
$(S R D)(\mathrm{d})$ over whole growth period $(\mathrm{GPw})$ of winter wheat. The station with a trend significant at the 0.05 level was marked by a flag.

stages (Fig. 4). On average, $T_{\max }$ decreased slightly during GP1 and GP4, however increased substantially during GP2 and GP3. $T_{\min }$ increased at all wheat growth stages, particularly during GP2 and GP3. $P$ had no obvious trend in any of the wheat growth stages. SRD decreased during GP1 and GP4 (Fig. 4).

\subsection{Partial correlation between annual yield and different climate variables at each growth stage}

During GPw, from all 34 stations, $T_{\max }$ and $T_{\min }$ were positively correlated with wheat yield at 18 and 20 stations, respectively, 


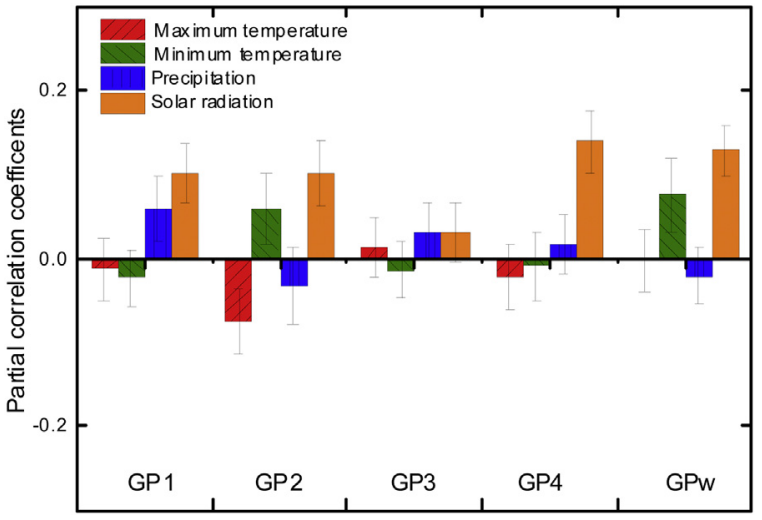

Fig. 6. Mean and standard error (represented by error bar) of partial correlation between annual wheat yield and maximum temperature (Tmax), minimum temperature (Tmin), precipitation $(P)$ and solar radiation $(S R D)$ at each growth stage of winter wheat across the 34 investigated stations.

although insignificantly at most of the stations (Fig. 5a, b). In contrast, they were negatively correlated with wheat yield at other stations in central and southern parts of the HHHP (Fig. 5b). $P$ was negatively correlated with wheat yield in the southern part of HHHP where annual precipitation was generally more than $600 \mathrm{~mm}$, and positively correlated to wheat yield in the northern part of HHHP where annual precipitation was generally less than $600 \mathrm{~mm}$ (Fig. 5c). SRD was positively correlated with wheat yield at most of the stations across the HHHP (Fig. 5d).

Across the stations in the HHHP, on average, wheat yields were positively correlated to $T_{\min }$ and particularly $S R D$ during $G P \mathrm{w}$, whereas they were little correlated to $T_{\max }$ and $P$ during $G P \mathrm{w}$, in the past three decades (Fig. 6). Through the different growth stages of winter wheat, wheat yield was positively correlated to $S R D$, positively correlated to $P$ at all growth stages except GP2 (Fig. 6), while negatively correlated to $T_{\max }$ and positively correlated to $T_{\min }$ during GP2.

\subsection{Sensitivity of winter wheat yield to different climate variables in each growth stage}

For each $1{ }^{\circ} \mathrm{C}$ increase in $T_{\max }$ during GPw, wheat yields increased more than $10 \%$ at some stations in the southern part, whereas they decreased generally more than $10 \%$ at several other stations throughout the HHHP (Fig. 7a). For each $1{ }^{\circ} \mathrm{C}$ increase in $T_{\text {min }}$ during $G P \mathrm{w}$, wheat yield increased more than $10 \%$ at some stations in the northern and southern part, whereas it decreased more than $10 \%$ at some stations in the southern part of the HHHP (Fig. 7b). The response of wheat yield to $T_{\max }$ and $T_{\min }$ was opposite at many stations. With a precipitation decrease by $10 \%$, wheat yield decreased up to $3 \%$ at some stations in the northern and western part, but increase up to $7 \%$ at some stations in the southern part of the HHHP (Fig. 7c). With a decrease in SRD by $10 \%$, wheat yield would decrease at most of the stations, and by more than $20 \%$ at some stations (Fig. 7d).

Using one sample $t$-test, across the 34 stations, we found the sensitivity of yield to $T_{\max }$ is not significantly different from $0.0(\mathrm{t}=0.04$, $\mathrm{df}=33, p$-value $=0.97)$, the sensitivity of yield to $T_{\min }$ is significantly greater than $0.0(\mathrm{t}=2.01, \mathrm{df}=33, p$-value $=0.05)$, the sensitivity of yield to $P$ is not significantly different from $0.0(t=-0.49, \mathrm{df}=33, p$ value $=0.63)$, the sensitivity of yield to SRD is significantly greater than $0.0(\mathrm{t}=3.55, \mathrm{df}=33, p$-value $=0.0012)$. Across the stations in the HHHP, wheat yields increased on average by $7.2 \%$ for each $1{ }^{\circ} \mathrm{C}$ increase in $T_{\min }$ during GPw, however decreased by $7.4 \%$ with $S R D$ decreasing by $10 \%$ during GPw. The yield sensitivity to changes in $T_{\max }$ and $P$ were relatively smaller on average (Fig. 8). The sensitivity of wheat yield to climate variables was variable in different growth stages (Fig. 8). Wheat yield was most sensitive to SRD change during GP4 and to $T_{\min }$ change during GP2.

\subsection{Yield change due to climate trends during the period of 1981-2009}

Increasing trends in $T_{\max }$ during GPw in 1981-2009 increased wheat yields at some stations in the southern part of HHHP by 0-30\%; however reduced it in the northeastern part of HHHP by $0-30 \%$, and by more than $30 \%$ in three stations in the southern part (Fig. 9a). By contrast, increasing trends in $T_{\text {min }}$ during GPw increased wheat yield at most stations across the HHHP; however reduced it at some stations in the southwestern part of HHHP (Fig. 9b). Decreasing trends in $P$ during GPw reduced wheat yield by $\sim 5 \%$ at some stations in the northern and western part of the HHHP, however increasing trends in $P$ reduced wheat yield by $\sim 5 \%$ at some stations in southern part of the HHHP (Fig. 9c). Decreasing trends in $S R D$ during $G P \mathrm{w}$ reduced wheat yield generally by $\sim 10.0 \%$ at most of the stations across the HHHP (Fig. 9d). Climate trends jointly increased wheat yield by $\sim 30 \%$ (or $1.0 \%$ per year) at 23 stations in eastern and southern parts of HHHP; however reduced it by $\sim 30 \%$ (or $1.0 \%$ per year) at 11 stations in the western part of HHHP (Fig. 9e). The results were generally similar to the estimates by the approach that accounts for the climate trends at each growth stage of winter wheat (i.e., Eq. (9)) (Fig. 9f).

Across the stations in the HHHP, during 1981-2009, wheat yields increased on average by $14.5 \%$ with increasing trends in $T_{\min }$ during GPw, however decreased by $3.0 \%$ with decreasing trends in SRD during GPw (Fig. 10). Trends in $T_{\max }$ and $P$ had relatively smaller impacts on wheat yields. In different growth stages of winter wheat, the impacts of climate trends on final yield were quite different (Fig. 10). In particular, the decreasing trend in SRD during GP1, GP2 and GP4 generally reduced wheat yield (Fig. 10). The increasing trend in $T_{\text {min }}$ during GP2 increased wheat yield largely by about $10 \%$ (Fig. 10 ).

\section{Discussion}

\subsection{Climate warming and the cardinal temperature thresholds of winter wheat in the HHHP}

Temperature has a complex effect on development and productivity of winter wheat due to its strong interaction with vernalization, photoperiod (Miglietta et al., 1995), photosynthesis and respiration (Porter and Gawith, 1999). In different growth and development stages, winter wheat has different temperature thresholds, optimum temperatures and sensitivities (Slafer and Rawson, 1995; Porter and Gawith, 1999). To get further insights into the impact of temperature on winter wheat yield at different growth stages, we selected four representative stations to compare the temperature conditions with the cardinal temperature thresholds of winter wheat in different growth stages (Fig. 11). The selected four stations were Huanghua in Hebei province (Fig. 11a), Zhumadian in Henan province (Fig. 11b), Weifang in Shandong province (Fig. 11c) and Linfen in Shanxi province (Fig. 11d). The cardinal temperature thresholds (i.e., base $\left(\mathrm{T}_{\text {min }}\right)$, optimum $\left(\mathrm{T}_{\mathrm{opt}}\right)$ and maximum ( $\mathrm{T}_{\max }$ ) temperatures) for different phenological processes (sowing to emergence, vernalization, terminal spikelet, anthesis and grain-filling phases) in wheat, identified by Porter and Gawith (1999) on basis of literature, are also shown in Fig. 11. We found that average daily $T_{\min }, T_{\text {mean }}$ and $T_{\max }$ during 1996-2008 were higher than these during 1981-1995 at all the four stations, especially from dormancy to anthesis (Fig. 11). For all the four stations, the temperatures during 1981-2009 were generally between 


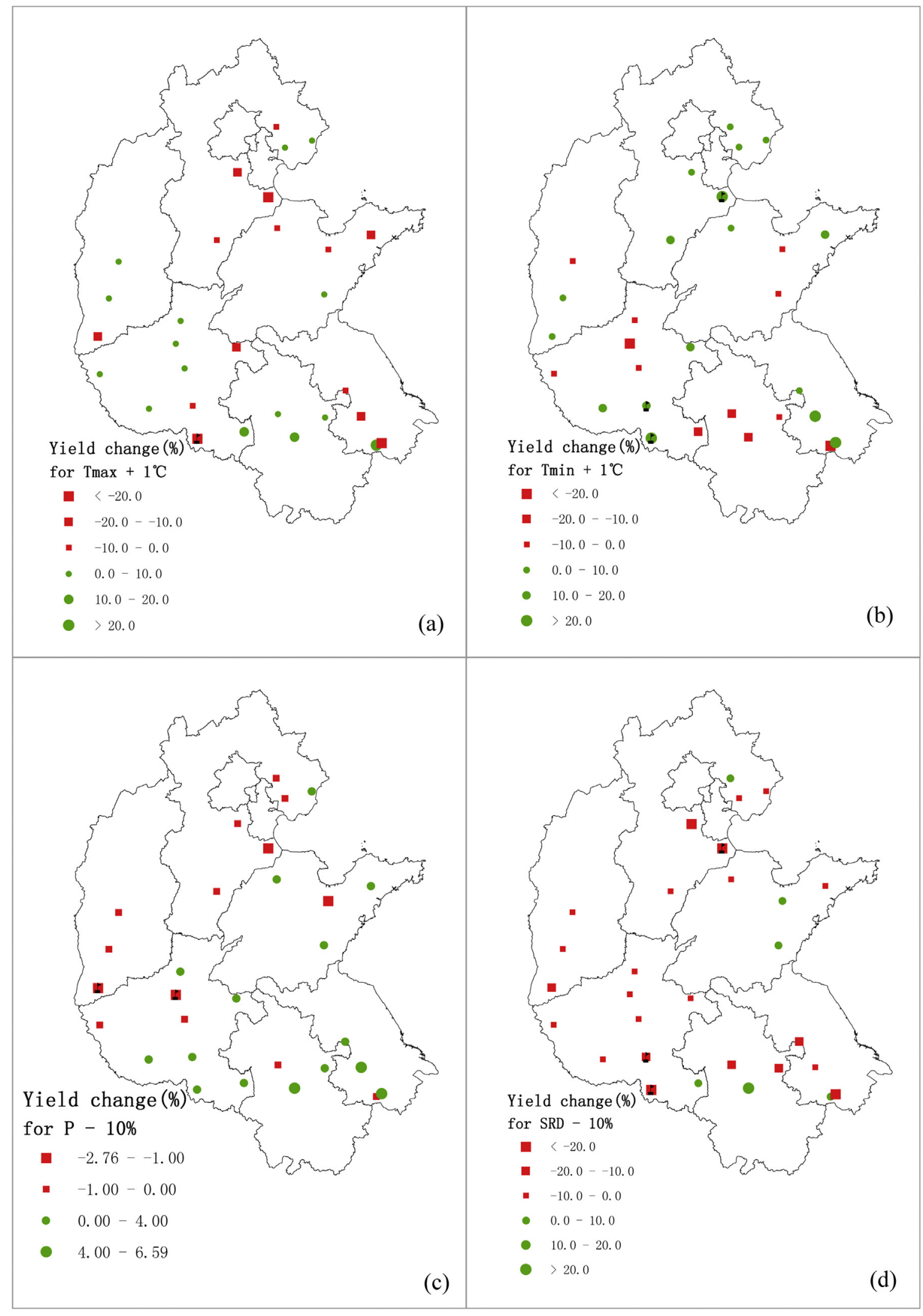

Fig. 7. Wheat yield change for maximum temperature (Tmax) increase by $1{ }^{\circ} \mathrm{C}(\mathrm{a})$, minimum temperature (Tmin) increase by $1{ }^{\circ} \mathrm{C}(\mathrm{b})$, precipitation (P) decrease by $10 \%(\mathrm{c})$, and solar radiation (SRD) decrease by $10 \%$ (d) during whole growth period (GPw) of winter wheat, respectively. Stations with a trend significant at the 0.05 level are marked by a flag. 


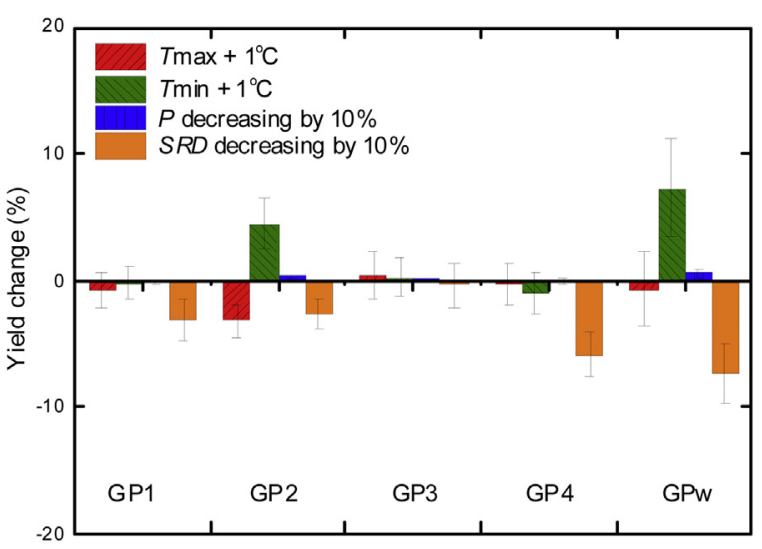

Fig. 8. Mean and standard error (represented by error bar) of wheat yield changes for maximum temperature (Tmax) increase by $1^{\circ} \mathrm{C}$, minimum temperature ( $T \mathrm{~min}$ ) increase by $1{ }^{\circ} \mathrm{C}$, precipitation $(P)$ decrease by $10 \%$, and solar radiation $(S R D)$ decrease by $10 \%$ at each growth stage of winter wheat across the 34 investigated stations.

the cardinal temperature thresholds during sowing to emergence, terminal spikelet, anthesis, and grain-filling phases, whereas below the $\mathrm{T}_{\text {min }}$ for some time during winter or early spring (vernalization phase; GP2). The mean temperatures were generally less than the $\mathrm{T}_{\text {opt }}$ at all phases except grain-filling, suggesting climate warming during 1981-2009 should be generally beneficial to winter wheat, however could be harmful for grain-filling at some stations. The frost damage during GP2 and high temperature stress during GP4 are potential challenges. In fact, the two kinds of extreme temperature stresses have happened frequently in the past three decades (Li et al., 2005; Zhang et al., 2014).

\subsection{Complex response of wheat yield to $\mathrm{T}_{\min }$ and $\mathrm{T}_{\max }$ in different growth stages}

We found that wheat had a different response to temperature at each growth stage (Fig. 8). Moreover, $T_{\max }$ and $T_{\min }$ had opposing impacts on yield at many stations (Fig. 7). In the northern part of HHHP, low temperatures in winter and early spring are important stress factors affecting wheat growth, and often cause damage or even death of wheat seedlings and thus causing yield reduction (Li et al., 2005). Warming trends during GP1 could accelerate wheat development and increase risk of cold injury at following growth stage. The temperature during GP2 was below the optimal temperature for winter wheat growth (Fig. 11), increase in $T_{\min }$ at this growth stage reduced cold injury and frost damage on winter wheat seedlings (Lu and Fan, 2013). Therefore, increase in $T_{\min }$ during GP2 was beneficial to wheat growth at many stations across the HHHP, however increase in $T_{\max }$ may affect vernalization. During GP3, the stage of the terminal spikelet initiation is important because it marks the end of the initiation of spikelet primordial and thus potential grain sets, which is known to be highly sensitive to temperature (Slafer and Savin, 1991). $\mathrm{T}_{\text {opt }}$ for this stage is between 9.3 and $11.9^{\circ} \mathrm{C}$ (Porter and Gawith, 1999). High temperature can reduce the number of spikelets per spike or the number of seeds per spikelet (Slafer and Savin, 1991). During GP4, warming could shorten the duration of grain filling by increasing the rate of grain filling if temperature is above $20^{\circ} \mathrm{C}$ (Wardlaw and Moncur, 1995; Asseng et al., 2011; Tao and Zhang, 2013). However actually temperature had a small effect on wheat yield on average because $T_{\max }$ decreased slightly due to advances in anthesis date. $T_{\text {min }}$ had negative impacts on wheat yield at some stations (Fig. 8) because respiration losses may increase (Ryan, 1991), grainfilling duration may reduce (Hunt et al., 1991; Wheeler et al., 1996a) and endosperm cell size during the ripening phase may decrease (Morita et al., 2005). In addition, high temperature episodes occur- ring close to the anthesis stage could induce spikelet sterility due to reduced pollen production (Wheeler et al., 1996a,b). Furthermore, high temperature $\left(>31^{\circ} \mathrm{C}\right)$ after anthesis could decrease the rate of grain-filling (Stone et al., 1995; Ferris et al., 1998) partly because the leaf photosynthetic apparatus can be damaged at extreme canopy temperatures, resulting in an acceleration of senescence (Wheeler et al., 1996b; Asseng et al., 2011; Lobell et al., 2012). Our analyses showed that $T_{\max }$ sometimes reached the extremes that cause the negative impacts at some stations. With climate warming, mean dates of anthesis and maturity were advanced (Fig. 2), which made the grain-filling phase to escape high temperature stress at some stations to some extent.

\subsection{Comparisons with other studies}

Due to the differences in models (process-based crop models and statistical models), crop production and climate data, model settings and assumptions, the estimated impacts of climate change on crop yields can be quite different. For example, studies using process-based crop models, without changing cultivars and management practices, showed that climate change had negative impacts on crop yields in the past three decades in the HHHP due to reduction of growth duration (e.g., Liu et al., 2010; Asseng et al., 2015). The studies using statistical models, census data at county scale and fixed crop growth seasons showed climate change had both positive and negative impacts on crop yields with a spatially varying pattern (e.g., Tao et al., 2012b; Zhang and Huang, 2013; Xiong et al., 2014). The estimated wheat yield change due to temperature trends in the past three decades ranged from -10 to $10 \%$ in the HHHP (Tao et al., 2012b), with positive change dominant (Tao et al., 2012b; Zhang and Huang, 2013; Xiong et al., 2014). Recently some studies used statistical analysis or/and crop modeling to investigate the impacts of climate change on wheat phenology and productivity in China (e.g., Tao et al., 2012a; Xiao et al., 2013; Wang et al., 2012, 2013; Liu et al., 2014; He et al., 2015; Yang et al., 2015). These studies showed that if adaptations such as shifts of sowing date and cultivars were not taken into account, climate warming in the past decades advanced wheat phenology and reduced wheat growth duration (Wang et al., 2013; Xiao et al., 2013; He et al., 2015), increased heat resources (Yang et al., 2015), and extreme high temperature reduced wheat yield (Liu et al., 2014). However, wheat production has been adapting to climate change through shifts of sowing dates, cultivars and agronomic management practices (Liu et al., 2010; Tao et al., 2012a), and as a result, wheat reproductive growth duration was actually increased (Xiao et al., 2013) and wheat yield were generally benefited from temperature increase in the HHHP (Wang et al., 2013; Xiao and Tao, 2014), suggesting climate impacts on crop growth and yield should be estimated taking adaptations into accounted (Tao et al., 2014). Along this line, this present study provided more specific estimates of climate impacts on wheat yields using trial data at experimental stations. By matching weather variables to farmspecific planting and harvesting dates and crop growth phases, this present study took autonomous adaptation into account, including shifts in sowing date, crop varieties and management practices. The results showed that climate change in the past three decades generally had positive impacts on wheat growth and yields in the major wheat production region under the interactions between climate change, genetics and management. The results are supported by recent artificial warming field experiments (Tian et al., 2014; Fang et al., 2015). For examples, in Jiangsu province in the southern HHHP, Tian et al. (2014) documented that an increase of $1.5^{\circ} \mathrm{C}$ in daily, daytime and nighttime mean temperatures shortened the length of pre-anthesis period significantly, by on average by $12.7,8.3$ and 10.7 days, respectively. It had no significant impact on the length of the post-anthesis period, however. Warming did 

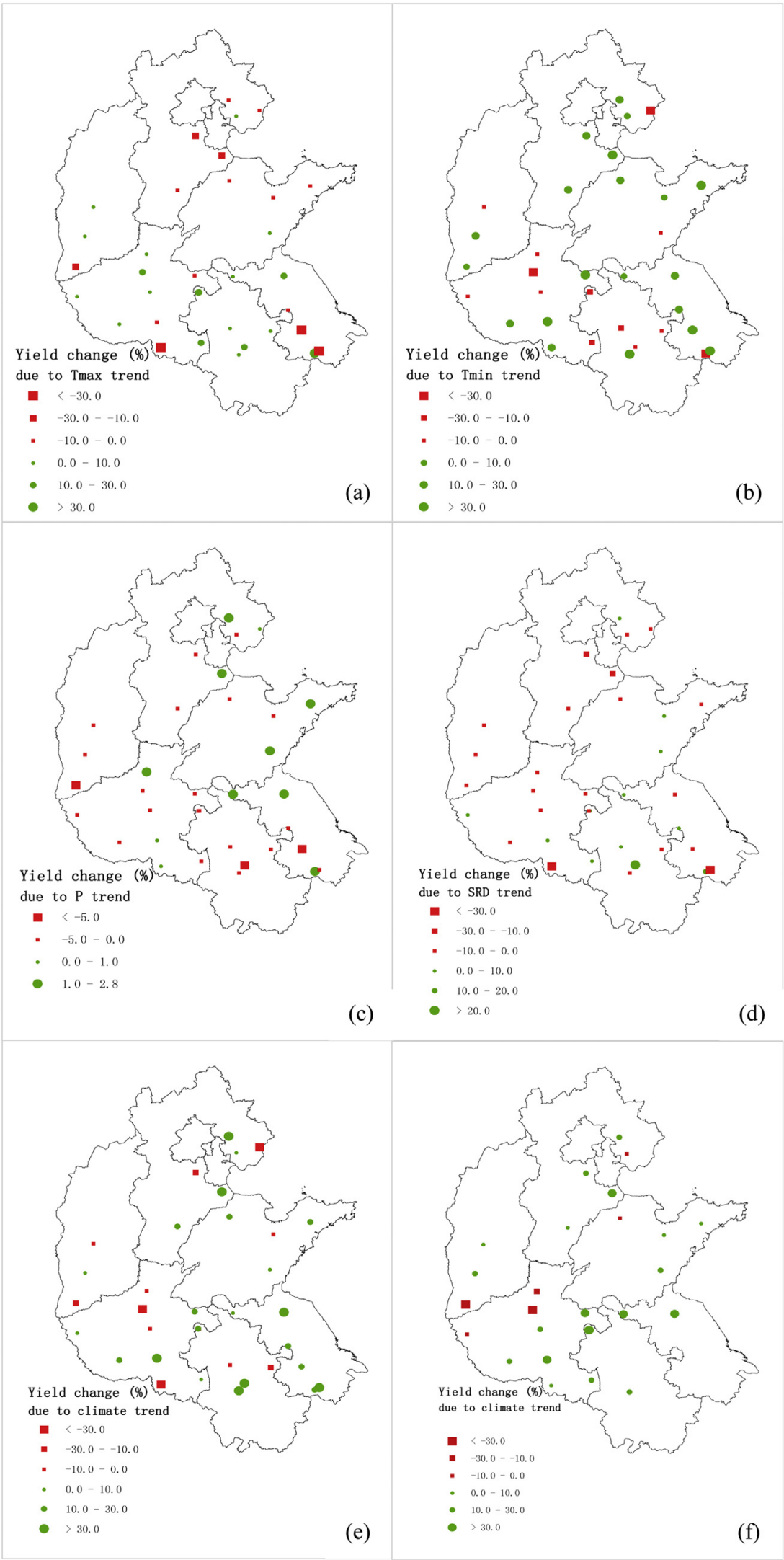

Fig. 9. Wheat yield change due to trend in maximum temperature (Tmax) (a), minimum temperature (Tmin) (b), precipitation (P) (c), solar radiation (SRD) (d), and climate jointly (e) during whole growth period (GPw) of winter wheat, respectively. (f) shows wheat yield change due to the trend in climate jointly estimated by the multiple regression model accounting for the climate trends at each growth stage of winter wheat. 
not significantly alter the aboveground biomass production, but the grain yield was significantly 16.3, 18.1 and $19.6 \%$ higher in the all-day warming, daytime warming and nighttime warming plots compared to the non-warmed plot, respectively. In Hebei province in the northern HHHP, Fang et al. (2015) documented that with a mean air temperature increase of $2.0-2.5^{\circ} \mathrm{C}$, overall wheat biomass increased by $30 \%$ and yield by $20 \%$ relative to a cold year. Grain yield in the cold year decreased by $37 \%$ because the number of days of minimum temperature below $0{ }^{\circ} \mathrm{C}$ increased by 14 days. The results are also supported by several crop modeling studies that account for adaptations to some extent (e.g., Wang et al., 2012; Tao and Zhang, 2013; Xiao and Tao, 2014). For example, Tao and Zhang (2013) showed that climate change can enhance the development and photosynthesis rate. The duration of reproductive period could be less affected than that of vegetative period, and wheat productivity could benefit from enhanced photosynthesis due to climate change and rising $\mathrm{CO}_{2}$. Xiao and Tao (2014) showed that during 1980-2009, cultivars renewal contributed to yield increase by $12.2-22.6 \%$; fertilization management contributed to yield increase by $2.1-3.6 \%$; temperature increase increased yield by $3.0-6.0 \%$ but reduced it by $12.0 \%$ for rainfed wheat; decrease in solar radiation reduced yield by $3.0-12.0 \%$ across the stations; climate change jointly contributed to yield generally by -3.0 to $3.0 \%$.
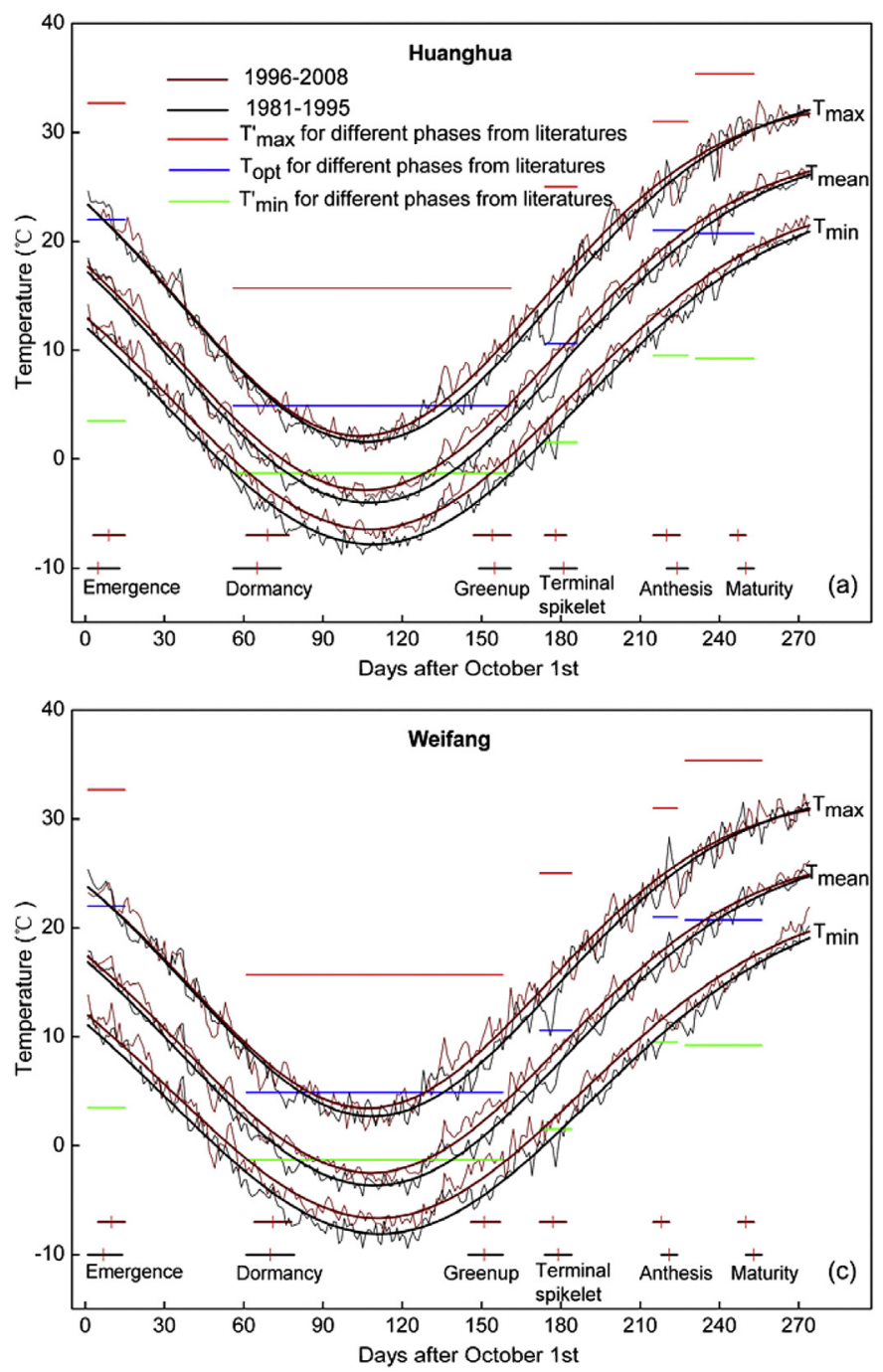

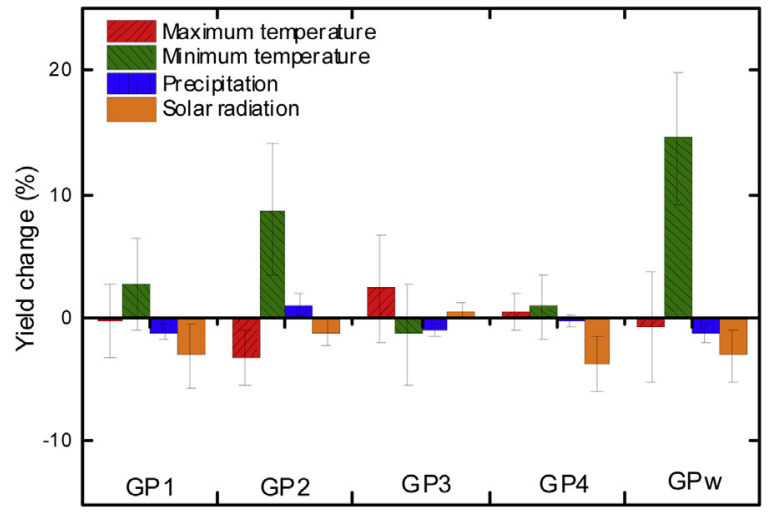

Fig. 10. Mean and standard error (represented by error bar) of wheat yield changes due to trends in maximum temperature ( $T$ max), minimum temperature ( $T \mathrm{~min})$, precipitation $(P)$, and solar radiation $(S R D)$ at each growth stage of winter wheat across the 34 investigated stations.

Recently, Liu et al. (2016) showed that grid-based and pointbased crop model simulations and statistical regressions produced similar estimates at global and national scales that global wheat yield was projected to decline between $4.1 \%$ and $6.4 \%$ with a $1{ }^{\circ} \mathrm{C}$
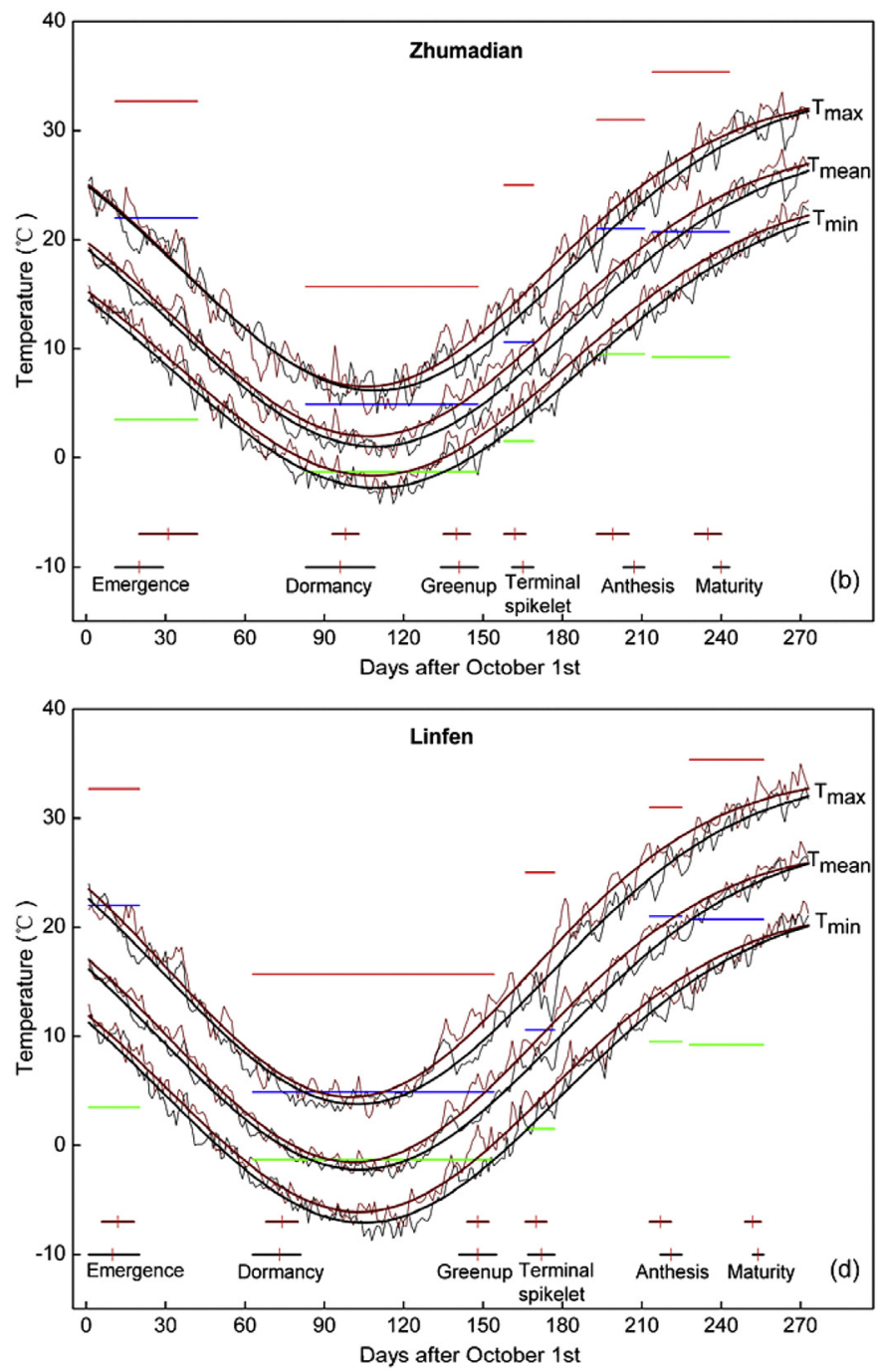

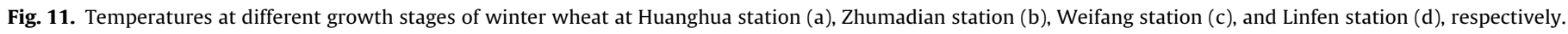
The cardinal temperature thresholds for different phases of wheat identified by Porter and Gawith (1999) are also shown. 
global temperature increase. The study scales were much larger and didn't take adaptation or $\mathrm{CO}_{2}$ fertilization effects into accounted (Liu et al., 2016). Also the study periods focused on the future. All these facts make the comparisons between Liu et al. (2016) and the current study difficult. For both crop modeling simulations and statistical analyses, among other things, the study settings, for example, whether allowing cultivar and sowing date adaptation with a changing climate, can affect the results notably (Porter et al., 2014; Tao et al., 2014). In addition, the estimates at global and national scales can be totally different from those at local scales that are often diverse. Furthermore, the quality of crop production and climate data, the temporal and spatial resolutions of the data, and the analysis methods are all the important factors that affect the results. At local scales, the estimates based on the artificial warming field experiments and valuable long-term historical field crop trial data are more robust and can help in gaining important insights into climate impacts on crop growth and productivity.

\subsection{Implications of climate impacts for winter wheat production in the HHHP and other wheat-growing regions in the world}

Across the 34 stations, from 1981 to 2009, mean wheat yield was $4857.0 \mathrm{~kg} / \mathrm{ha}$ although have a quite large spatial variation, which ranged from $337.5 \mathrm{~kg} / \mathrm{ha}$ to $9810.5 \mathrm{~kg} / \mathrm{ha}$ with standard deviation being $1558.6 \mathrm{~kg} / \mathrm{ha}$ (Fig. S1). From 1981-2009, due to improvements in genotype and agronomic management such as fertilization and irrigation, winter wheat yield increased $80.5 \mathrm{~kg} / \mathrm{ha} /$ year or $1.7 \%$ per year on average. As indicated in this study, shifts in sowing dates and adoptions of cultivars with higher thermal requirements and longer reproductive growth duration have been effective options. In contrast, during this period, climate trends jointly increased wheat yield by $1.0 \%$ per year at 23 stations, however reduced it by $1.0 \%$ per year at 11 stations. Therefore, climate impacts on wheat growth and yield have been large enough to be worthy of attention in the HHHP. The other important concern is that solar radiation has declined significantly although with less degree. Crop productivity is highly sensitive to change in solar radiation in the HHHP. The declining solar radiation has partly offset the benefits of increasing temperature or aggravated yield together with increasing temperature at some stations. The estimated interaction effects of temperature increase with declining solar radiation are consistent with our previous crop modeling studies (Xiao and Tao, 2014). Since the declining solar radiation in the HHHP is manly ascribed to increasing air pollutants such as aerosol, therefore, the strategies should be elaborated to reduce the emission of air pollutants.

The findings of this study have also important implications for other wheat-growing regions in the world. Several studies showed that without adaptation rising temperatures and increasing temperature variability would reduce global wheat production notably in major wheat cultivation regions and countries such as China, USA, India, France, Russia and Australia (Asseng et al., 2011, 2015; Liu et al., 2016; Lobell et al., 2011a,b, 2012). This study showed that adaptations at local scales such as shifts of sowing dates, cultivars and agronomic management could cope with climate change and take the advantage of the improved heat resources from climate change. Therefore, the major wheat cultivation regions should try to develop effective adaptations strategies and options to cope with climate change.

\section{Conclusions}

Based on the crop trial data from 34 agro-meteorological stations during 1981-2009, several statistical approaches such as partial correlation analyses and multiple regression models were used to investigate the climate impacts on winter wheat growth and yields in the Huang-Huai-Hai Plain (HHHP). The long-term historical field crop trial data allowed us to examine how weather affects yields in a setting in which autonomous adaptation such as changes in sowing dates, cultivars and management practices were taken based on actual weather. These not only make our estimates of climate impacts on wheat growth and yields more robust, but also allowed us to gain insights into climate change impacts and adaptations at local scales.

The results highlight the different impacts of $T_{\max }$ and $T_{\min }$ in different growth stages of winter wheat, as well as the importance of management and cultivars in adapting to climate change in the major wheat production region. The results suggest that ongoing climate change in coming decades during GPw will generally favor wheat production in a large area of the HHHP, specifically the increase in minimum temperature in the period from winter dormancy to greenup. These findings are robust, corroborated by several empirical statistical analyses, local experiences, artificial warming field experiments, as well as previous crop modeling studies that account for adaptations.

Climate impacts on wheat growth and yield have been large enough to be worthy of attention in the HHHP. In the long term, the warming trend and specifically high temperatures during the grain-filling stage will however have negative effects on wheat yield, because the current temperatures are approaching or have already exceeded the optimum temperature range at some stations. Like many other important wheat growing regions of the world, integrated approaches including genotypic adaptation and system agronomic management should be developed to address the likely effects of climate extremes on wheat.

\section{Acknowledgements}

This study is supported by the National Science Foundation of China (Project Nos. 41571088, 31561143003 and 41571493). Funding support by the FACCE MACSUR project through the Finnish Ministry of Agriculture and Forestry is also gratefully acknowledged.

\section{Appendix A. Supplementary data}

Supplementary data associated with this article can be found, in the online version, at http://dx.doi.org/10.1016/j.agrformet.2017. 02.033 .

\section{References}

Asseng, S., Foster, I., Turner, N.C., 2011. The impact of temperature variability on wheat yields. Global Change Biol. 17, 997-1012.

Asseng, S., Ewert, F., Martre, P., Rötter, R.P., Lobell, D.B., et al., 2015. Rising temperatures reduce global wheat production. Nat. Clim. Change 5, 143-147.

Fang, S., Cammarano, D., Zhou, G., Tan, K., Ren, S., 2015. Effects of increased day and night temperature with supplemental infrared heating on winter wheat growth in North China. Eur. J. Agron. 64, 67-77.

Ferris, R., Ellis, R.H., Wheeler, T.R., Hadley, P., 1998. Effect of high temperature stress anthesis on grain yield and biomass of field-grown crops of wheat. Annals Bot. 82, 631-639.

Gornall, J., Betts, R., Burke, E., Clark, R., Camp, J., Willett, K., Wiltshire, A., 2010. Implications of climate change for agricultural productivity in the early twenty-first century. Phil. Trans. R. Soc. B 365, 2973-2989.

He, L., Asseng, S., Zhao, G., Wu, D., Yang, X., Zhuang, W., Jin, N., Yu, Q., 2015. Impactsof recent climate warming, cultivar changes, and crop management on winterwheat phenology across the Loess Plateau of China. Agric. For. Meteorol. 200, 135-143.

Hunt, L.A., van der Poorten, G., Pararajasingham, S., 1991. Postanthesis temperature effects on duration and rate of grain-filling in some winter and spring wheat. Can. J. Plant Sci. 71, 609-617.

Li, M.S., Wang, D.L., Zhang, Q., Chi, Y.G., Wang, C.Y., Kiribuchi-Otobe, C., Yoshida, H., 2005. Cause analysis of frost damage to winter wheat in Huang-Huai-Hai plain during 2004-2005. J. Nat. Hazards 14, 51-55 (in Chinese with English abstract). 
Liu, Y., Wang, E.L., Yang, X.G., Wang, J., 2010. Contributions of climatic and crop varietal changes to crop production in the North China Plain since 1980. Global Change Biol. 16, 2287-2299.

Liu, B., Liu, L., Tian, L., Cao, W., Zhu, Y., Asseng, S., 2014. Post-heading heat stressand yield impact in winter wheat of China. Global Change Biol. 20, 372-381.

Liu, B., Asseng, S., Müller, C., Ewert, F., Elliott, J., et al., 2016. Similar estimates of temperature impacts on global wheat yield by three independent methods. Nat. Clim. Change 6, 1130-1136.

Lobell, D.B., Asner, G.P., 2003. Climate and management contributions to recent trends in U.S. agricultural yields. Science 299, 1032

Lobell, D.B., Burke, M.B., 2010. On the use of statistical models to predict crop yield responses to climate change. Agric. For. Meteorol. 150, 1443-1452.

Lobell, D.B., Schlenker, W., Roberts, J.C., 2011a. Climate trends and global crop production since 1980. Science 333, 616-620.

Lobell, D.B., Banziger, M., Magorokosho, C., Vivek, B., 2011b. Nonlinear heat effects on African maize as evidenced by historical yield trials. Nat. Clim. Change 1, $42-45$.

Lobell, D.B., Sibley, A., Ivan Ortiz-Monasterio, J., 2012. Extreme heat effects on wheat senescence in India. Nat. Clim. Change 2, 186-189.

Lu, C.H., Fan, L., 2013. Winter wheat yield potentials and yield gaps in the North China Plain. Field Crops Res. 143, 98-105.

Müller, C., Cramer, W., Hare, W.L., Campen, H.L., 2011. Climate change risks for African agriculture. Proc. Natl. Acad. Sci. U. S. A. 108, 4313-4315.

Miglietta, F., Tanasescu, M., Marica, A., 1995. The expected effects of climate change on wheat development. Global Change Biol. 1, 407-415.

Morita, S., Yonemaru, J., Takanashi, J., 2005. Growth and endosperm cell size under high night temperatures in rice (Oryza sativa L.). Ann. Bot. 95, 695-701.

Ortiz, R., Sayre, K.D., Govaerts, B., Gupta, R., Subbarao, G.V., Ban, T., Hodson, D., Dixon, J.A., Ortiz-Monasterio, J.I., Reynolds, M., 2008. Climate change: can wheat beatthe heat? Agric. Ecosys. Environ. 126, 46-58.

Palosuo, T., Rötter, R.P., Salo, T., Peltonen-Sainio, P., Tao, F., Lehtonen, H., 2015 Effects of climate and historical adaptation measures on barley yield trends in Finland. Clim. Res. 65, 221-236.

Peng, S., Piao, S., Ciais, P., Myneni, R.B., Chen, A.P., Chevallier, F., Dolman, A.J., Janssens, I.A., Penuelas, J., Zhang, G.X., Vicca, S., Wan, S.Q., Wang, S.P., Zeng, H., 2013. Asymmetric effects of daytime and night-time warming on Northern Hemisphere vegetation. Nature 501, 88-92.

Porter, J.R., Gawith, M., 1999. Temperatures and the growth and development of wheat: a review. Eur. J. Agron, 10, 23-36.

Porter, J.R., Xie, L., Challinor, A.J., Cochrane, K., Howden, S.M., Iqbal, M.M., Lobell D.B., Travasso, M.I., 2014. Food security and food production systems. In: Climate Change 2014: Impacts, Adaptation, and Vulnerability. Part A: Global and Sectoral Aspects. Contribution of Working Group II to the Fifth Assessment Report of the Intergovernmental Panel on Climate Change, Cambridge University Press, Cambridge, United Kingdom and New York, NY, USA, pp. 485-533.

Prescott, J.A., 1940. Evaporation from a water surface in relation to solar radiation. Trans. R. Soc. South Aust. 64, 114-118.

Rötter, R.P., Carter, T.R., Olesen, J.E., Porter, J.R., 2011. Crop-climate models need an overhaul. Nat. Clim. Change 1,175-177.

Ray, D.K., Gerber, J.S., MacDonald, G.K., West, P.C., 2015. Climate variation explains a third of global crop yield variability. Nat. Commun. 6, 5989.

Reidsma, P., Ewert, F., Lansink, A.O., Leemans, R., 2009. Vulnerability and adaptation of European farmers: a multi-level analysis of yield and income responses to climate variability. Reg. Environ. Change 9, 25-40.

Reidsma, P., Ewert, F., Lansink, A.O., Leemans, R., 2010. Adaptation to climate change and climate variability in European agriculture: the importance of farm level responses. Eur. J. Agron. 32, 91-102.

Ryan, M., 1991. Effects of climate change on plant respiration. Ecol. Appl. 1, $157-167$.

Sacks, W.J., Kucharik, C.J., 2011. Crop management and phenology trends in the US Corn Belt: impacts on yields, evapotranspiration and energy balance. Agric. Meteorol. 151, 882-894.

Slafer, G.A., Rawson, H.M., 1995. Base and optimum temperatures vary with genotype and stage of development in wheat. Plant Cell Environ. 18, 671-679.
Slafer, G.A., Savin, R., 1991. Developmental base temperature in different phenological phases of wheat (Triticum aestivum). J. Exp. Bot. 42 (241), 1077-1082.

Stone, P.J., Savin, R., Wardlaw, I.F., Nicolas, M.E., 1995. The influence of recovery temperature on the effects of a brief heat shock on wheat I. Grain growth. Aust. J. Plant Physiol. 22, 945-954.

Tao, F.L., Zhang, Z., 2013. Climate change, wheat productivity and water use in the North China Plain: a new super-ensemble-based probabilistic projection. Agric. For. Meteorol. 170, 146-165.

Tao, F.L., Zhang, S., Zhang, Z., 2012a. Spatiotemporal changes of wheat phenology in China under the effects of temperature, day length and cultivar thermal characteristics. Eur. J. Agron. 43, 201-212.

Tao, F.L., Zhang, Z., Zhang, S., Zhu, Z., Shi, W., 2012b. Response of crop yields to climate trends since 1980 in China. Clim. Res. 54, 233-247.

Tao, F., Zhang, Z., Xiao, D., et al., 2014. Responses of wheat growth and yield to climate change in different climate zones of China, 1981-2009. Agric. For. Meteorol. 189-190, 91-104.

Tian, Y., Zheng, C., Chen, J., Chen, C., Deng, A., Song, Z., Zhang, B., Zhang, W., 2014 Climatic warming increases winter wheat yield but reduces grain nitrogen concentration in east china. PLoS One 9 (4), e95108.

Wang, J., Wang, E.L., Yang, X.G., et al., 2012. Increased yield potential of wheat-maize cropping system in the North China Plain by climate change adaptation. Clim. Change 113 (3-4), 825-840.

Wang, J., Wang, E., Feng, L., Yin, H., Yu, W., 2013. Phenological trends of winterwheat in response to varietal and temperature changes in the North China Plain. Field Crops Res. 144, 135-144.

Wardlaw, I., Moncur, L., 1995. The response of wheat to high temperature following anthesis. I. The rate and duration of kernel filling. Funct. Plant Biol. 22, 391-397.

Welch, J.R., Vincent, J.R., Auffhammer, M., Moya, P.F., Dobermann, A., 2010. Rice yields in tropical/subtropical Asia exhibit large but opposing sensitivities to minimum and maximum temperatures. Proc. Natl. Acad. Sci. U. S. A. 107, $14562-14567$.

Wheeler, T.R., Batts, G.R., Ellis, R.H., Hadley, P., Morison, J.I.L., 1996a. Growth and yield of winter wheat (Triticum aestivum) crops in response to $\mathrm{CO}_{2}$ and temperature. J. Agric. Sci. 127, 37-48.

Wheeler, T.R., Hong, T.D., Ellis, R.H., Batts, G.R., Morison, J.I.L., Hadley, P., 1996b. The duration and rate of grain growth, and harvest index, of wheat (Triticum aestivum) in response to temperature and $\mathrm{CO}_{2}$. J. Exp. Bot. 47, 623-630.

White, J.W., Hoogenboom, G., Kimball, B.A., Wall, G.W., 2011. Methodologies for simulating impacts of climate change on crop production. Field Crops Res. 124, 357-368.

Xiao, D.P., Tao, F.L., 2014. Contributions of cultivars, management and climate change to winter wheat yield in the North China Plain in the past three decades. Eur. J. Agron. 52, 112-122.

Xiao, D.P., Tao, F.L., Liu, Y.J., Shi, W.J., Wang, M., Liu, F., Zhang, S., Zhu, Z., 2013. Observed changes in winter wheat phenology in the North China Plain for 1981-2009. Int. J. Biometeor. 57, 275-285

Xiong, W., Holman, I.P., You, L., Yang, J., Wu, W., 2014. Impacts of observed growing-season warming trends since 1980 on crop yields in China. Reg. Environ. Change 14, 7-16.

Yang, X.G., Chen, F., Lin, X.M., Liu, Z.J., Zhang, H.L., Zhao, J., Li, K.N., Ye, Q., Li, Y., Lv, S., 2015. Potential benefits of climate change for crop productivity in China. Agric. For. Meteorol. 208, 76-84.

Yang, S., 1991. The ten agricultural regions of China. In: Xu, G., Peel, L.J. (Eds.), The Agriculture of China. Oxford University Press, New York, pp. 108-143.

You, L.Z., Rosegrant, M.W., Wood, S., Sun, D.S., 2009. Impact of growing season temperature on wheat productivity in China. Agric. For. Meteorol. 149, 1009-1014.

Zhang, T., Huang, Y., 2013. Estimating the impacts of warming trends on wheat and maize in China from 1980 to 2008 based on county level data. Int. J. Climatol. 33, 699-708.

Zhang, Z., Wang, P., Chen, Y., Zhang, S., Tao, F., Liu, X., 2014. Spatial pattern and decadal change of agro-meterological disasters in the main wheat production area of China during 1991-2009. J. Geogr. Sci. 24, 387-396. 